\title{
Improved Process for Anti-Coagulant Drug Substance Rivaroxaban
}

\author{
T. Suresh and K. Rambabu \\ Department of Chemistry, RVR \& JC College of \\ Engineering, Chowdavaram Guntur, A.P, India
}

\section{ABSTRACT}

An anti-coagulant drug substance rivaroxaban is developed with improved process by introducing a new oxazolidine ring formation with commercially available carbamide in presence of strong base like potassium hydroxide in toluene as solvent and the developed process is scalable, economic than innovator process, which is mentioned in scheme 1.

\section{KEY WORDS: IMPROVED SYNTHESIS, ALTERNATIVE REAGENTS, RIVAROXABAN.}

\section{INTRODUCTION}

Rivaroxaban is an orally bioavailable member of a new class of potent and novel factor Xa inhibitors (oxazolidinone derivatives is used for the treatment and prevention of various thromboembolic ailments, especially deep venous thrombosis, pulmonary embolism, angina pectoris, myocardial infarction, cerebral stroke, restenosis after angioplasty or aortocoronary bypass, transitory ischemic attacks and the peripheral arterial occlusive diseases. It has also been used in the treatment of stroke and systemic embolism in adult patients with non-valvular atrial fibrillation and for the prevention of deep vein thrombosis. It has also been approved for the treatment of atherothrombotic events in patients who have high cardiac biomarkers.

In this accord great attention has been focused on the synthesis of rivaroxaban and as such many reviews have been published on the rivaroxaban. Whereas, the

\section{ARTICLE INFORMATION}

${ }^{*}$ Corresponding author email: la

Received 12th Oct 2020 Accepted after revision 30th Dec 2020 Print ISSN: 0974-6455 Online ISSN: 2321-4007 CODEN: BBRCBA

Thomson Reuters ISI Web of Science Clarivate Analytics USA and Crossref Indexed Journal

\section{Clarivate
Analytics}

NAAS Journal Score 2020 (4.31)

A Society of Science and Nature Publication,

Bhopal India 2020. All rights reserved.

Online Contents Available at: http//www.bbrc.in/

Doi: http://dx.doi.org/10.21786/bbrc/13.15/57
Author in his improved route of synthesis he developed with commercially viable and available reagents used for cyclization and as well as peptide bond formation This current paper describes an insight into the improved route synthesis of rivaroxaban that is commercially viable.

Experimental: Chemical \& Solvents:All the chemicals for the synthesis of rivaroxaban were supplied from Merck and Aldrich Chemicals \& Co. And used as received. All reactions were carried out with dry, freshly distilled solvents under anhydrous conditions.

The UV-Visible absorption spectra were recorded in DMSO with a SHIMADZU UV-1800 spectrometer at concentration range of 10-4 M. IR spectra were recorded in the region of $4000 \mathrm{~cm}-1$ to $400 \mathrm{~cm}-1$ on an FT-IR-Alpha Bruker IR spectrometer in $\mathrm{KBr}$ pellets. The 1H-and 13C-NMR spectra were recorded in DMSO-d6 at 500MHz using AV500-High Resolution Multinuclear FT-NMR Spectrometer with tetramethylsilane as internal standard.

\section{RESULTS AND DISCUSSION}

Improved process of synthesis of rivaroxaban was made by introducing a new oxazolidine ring formation with commercially available carbamide in presence of strong base like potassium hydroxide in toluene as solvent. The synthesized compound was analyzed and characterized by melting point, UV-Vis, IR, 1H-NMR, 13C NMR, and elemental analysis.

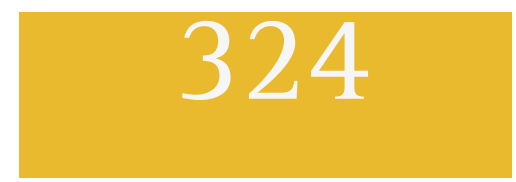


Process for the preparation of 2-(2-Hydroxy-3-((4-(3Oxomorpholino) Phenyl) Amino) Propyl) Isoindoline-1, 3-Dione (3): In a $500 \mathrm{ML}$ round bottom flask 50gm of 4-(4-aminophenyl) morpholin-3-one(1) and $45 \mathrm{gm}$ of 2-(oxiran-2-ylmethyl) isoindoline-1, 3-dione(2) was taken in a $300 \mathrm{ml}$ of Toluene at room temperature. Slowly rose the temperature up to $80-850 \mathrm{C}$ and maintained the reaction mass for 4-5 hours. After completion of the reaction, cooled the reaction mass temperature to room temperature and filtered through Buckner funnel. The obtained off-white solid was again purified in water and dried.

Process for the preparation of 2-((2-0xo-3-(4-(3Oxomorpholino) Phenyl) Oxazolidin-5-YI) Methyl) Isoindoline-1, 3-Dione (4): $34.5 \mathrm{gm}$ of 2-(2-hydroxy3-((4-(3-oxomorpholino) phenyl) amino) propyl) isoindoline-1, 3-dione (3) in $250 \mathrm{~mL}$ of Toluene was taken in a $500 \mathrm{ML}$ round bottom flask and added 50gm of carbamide, $22 \mathrm{gm}$ of potassium hydroxide. The reaction mass was refluxed for 10-11 hours. After completion of the reaction in thin layer chromatography monitoring cooled the reaction mass to room temperature and filtered the precipitated reaction mass to obtain a half white solid, which was further purified in water to get pure ring closured materials(4).

Process for the preparation of 4-(4-(5-(Aminomethyl)2-Oxooxazolidin-3-YI) Phenyl) Morpholin-3-One (5): $15 \mathrm{gm}$ of 2-((2-oxo-3-(4-(3-oxomorpholino) phenyl) oxazolidin-5-yl) methyl) isoindoline-1, 3-dione (4) was subjected to de-phthalation in $100 \mathrm{~mL}$ of $10 \%$ Ammonia in Isopropyl alcohol under reflux condition for 5-6 hours. Once reaction completed reaction mass was cooled to room temperature and filtered the light brown colored targeted product 5 good quality and yield.

Figure 1: Structure of rivaroxaban

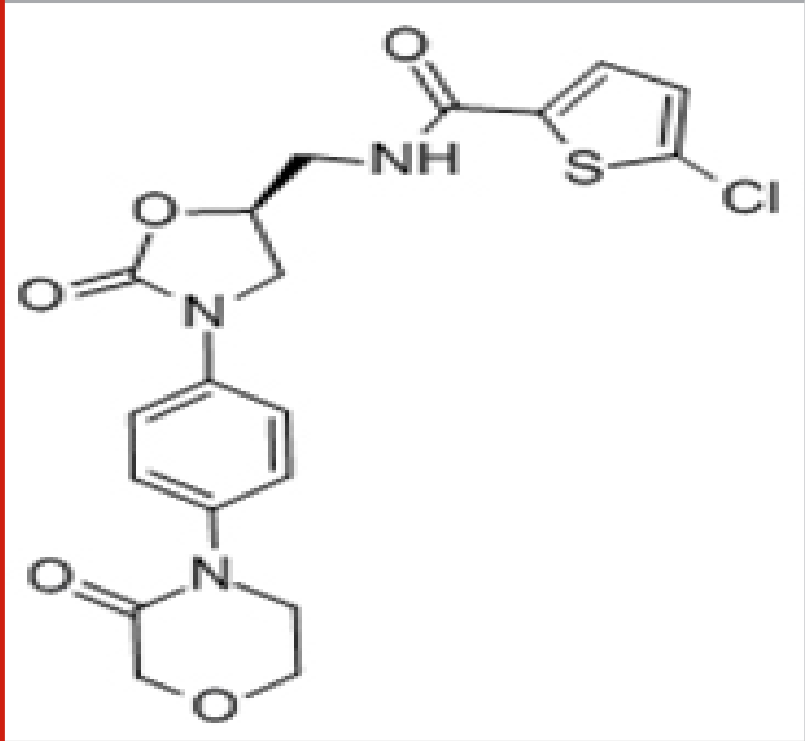

Process for the preparation of 5-Chloro- $\mathrm{N}-((2-0 \times 0-$ 3-(4-(3-0xomorpholino) Phenyl) Oxazolidin-5-YI) Methyl) Thiophene-2-Carboxamide (7): In a 1000mL round bottom flask $75 \mathrm{gm}$ of -(4-(5-(aminomethyl)-2oxooxazolidin-3-yl)phenyl)morpholin-3-one (5), $82 \mathrm{gm}$ of 5-chlorothiophene-2-carbonyl chloride (6) taken in 200 $\mathrm{mL}$ of N,N-Dimethyl amine (DMF) and 45gm of Potassium tertiary but oxide at room temperature and maintained it for 2-3 hours for completion of the reaction. After completion of the reaction $350 \mathrm{~mL}$ of Water was added to quench the reaction and the obtained white colored material was purified in ethyl acetate to get high pure material with any other impurity NMT 0.10\%.

Scheme 1: Route of Synthesis of rivaroxaban (Improved process route of synthesis)

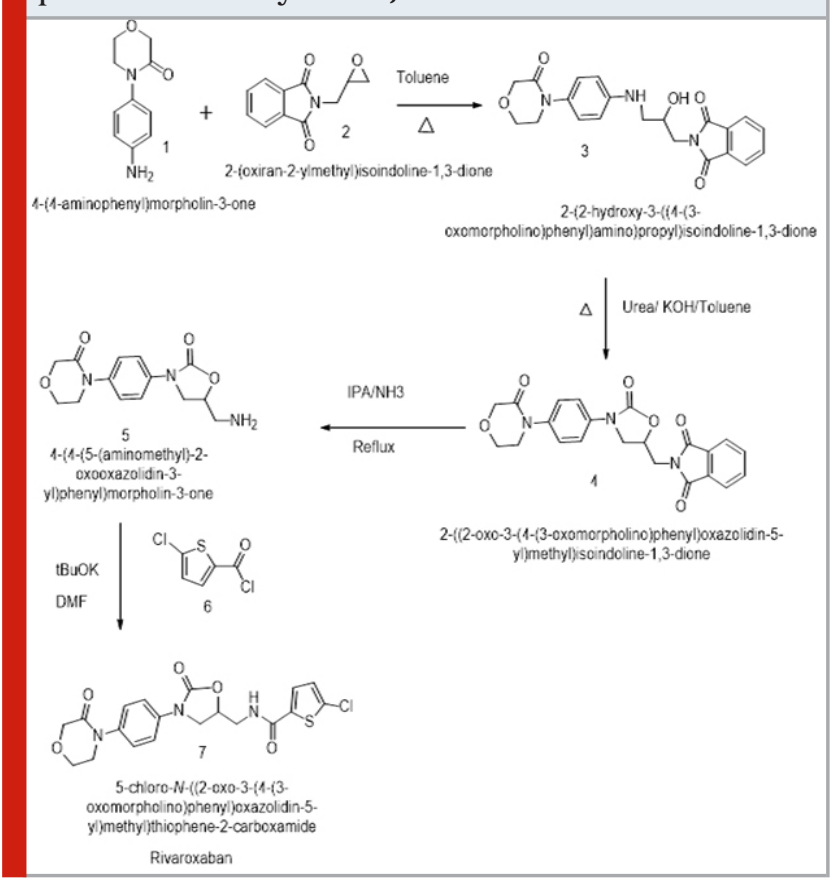

Figure 2: 1H NMR 2-(2-hydroxy-3-((4-(3-oxomorpholino) phenyl) amino) propyl) isoindoline-1, 3-dione

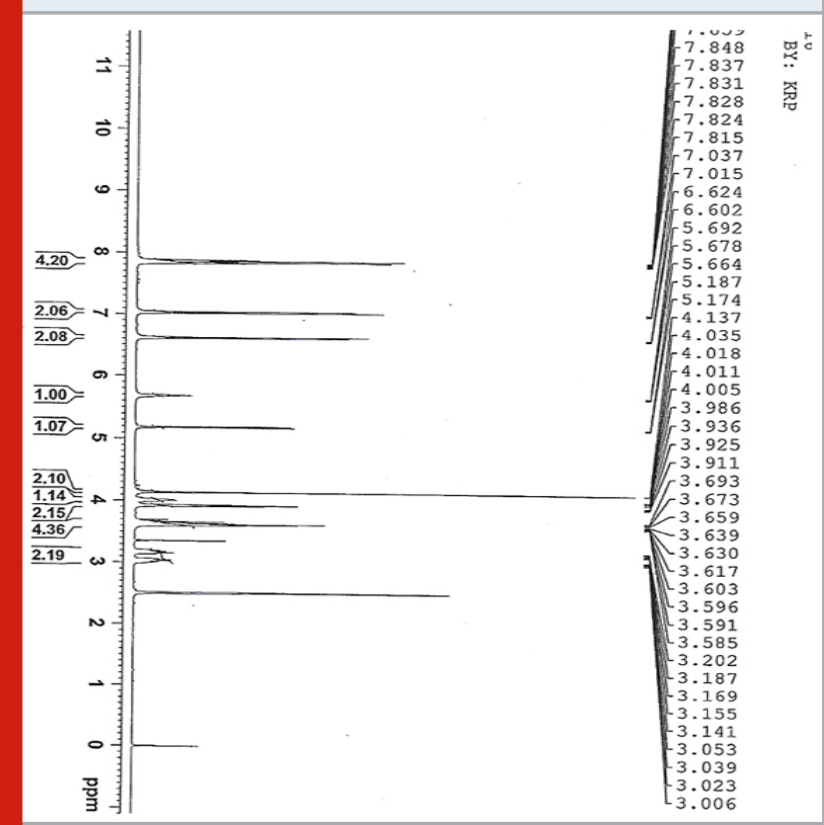


Figure 3: 13C NMR 2-(2-hydroxy-3-((4-(3-oxomorpholino) phenyl) amino) propyl) isoindoline-1, 3-dione

$$
\begin{aligned}
& \text { 20.2II- } \\
& \varepsilon 6^{\circ} \mathrm{ZZL} \\
& 87.92 \mathrm{~T} \\
& \text { ธE. } 0 \text { ¿ I } \\
& \text { 28. โยโ } \\
& 8 V^{\circ} \angle G \tau- \\
& 6 L \cdot 59[- \\
& 0 \tau \cdot 891= \\
& \text { 参 }
\end{aligned}
$$

○ :

Figure 5: FT-IR 2-(2-hydroxy-3-((4-(3-oxomorpholino) phenyl) amino) propyl) isoindoline-1, 3-dione

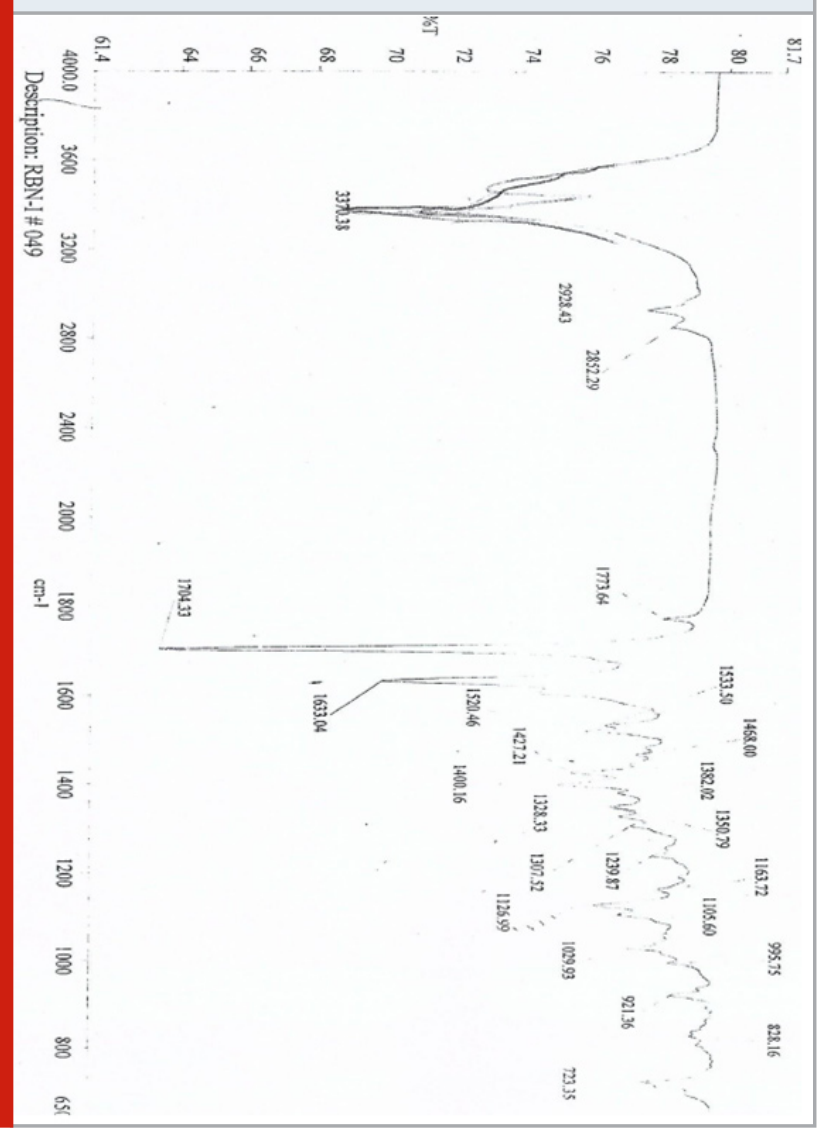

Figure 4: Mass 2-(2-hydroxy-3-((4-(3-oxomorpholino) phenyl) amino) propyl) isoindoline-3-dione

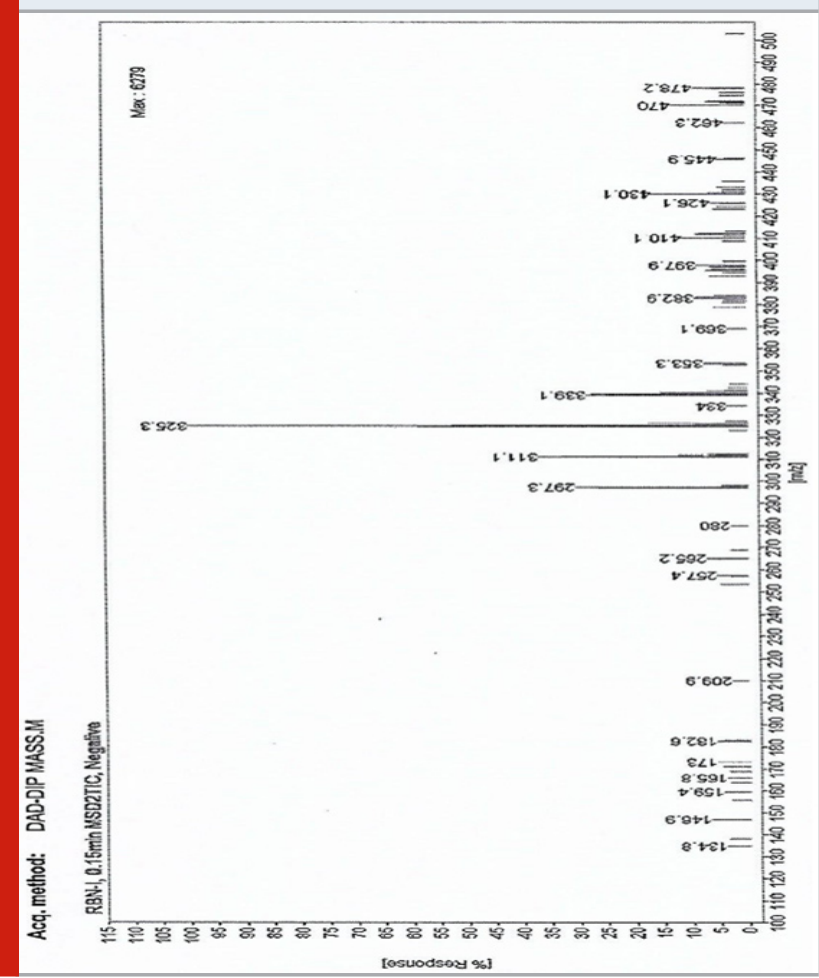

Figure 6: 1H NMR 2-((2-oxo-3-(4-(3-oxomorpholino) phenyl) oxazolidin-5-yl) methyl) isoindoline-1, 3-dione

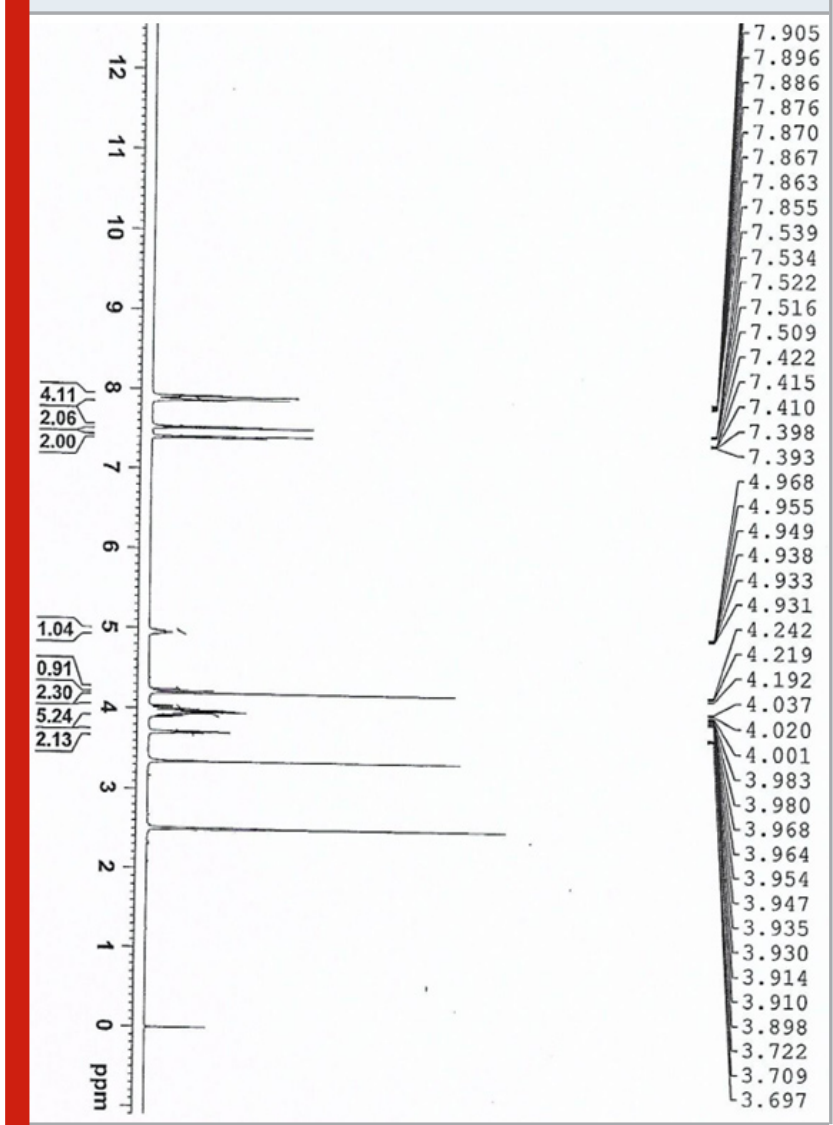


Figure 7: 13C NMR 2-((2-oxo-3-(4-(3-oxomorpholino) phenyl) oxazolidin-5-yl) methyl) isoindoline-1, 3-dione

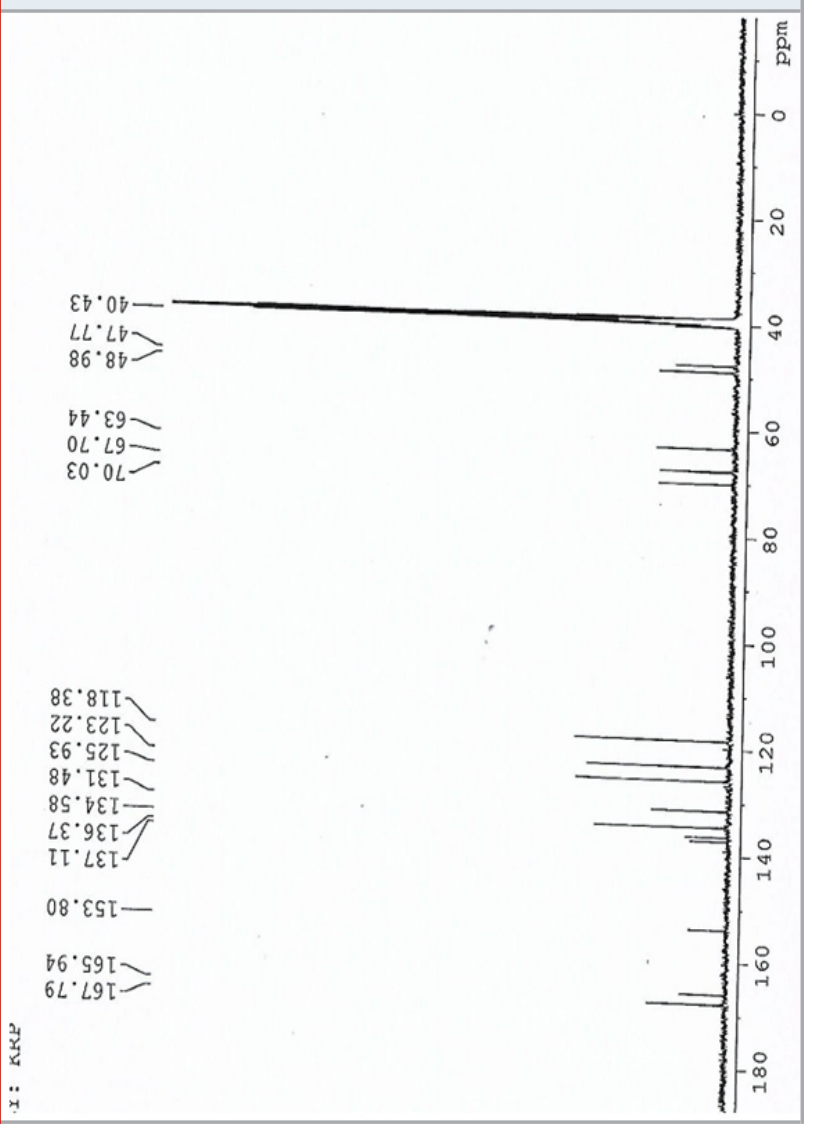

Figure 9: FT-IR 2-((2-oxo-3-(4-(3-oxomorpholino) phenyl) oxazolidin-5-yl) methyl) isoindoline-1, 3-dione

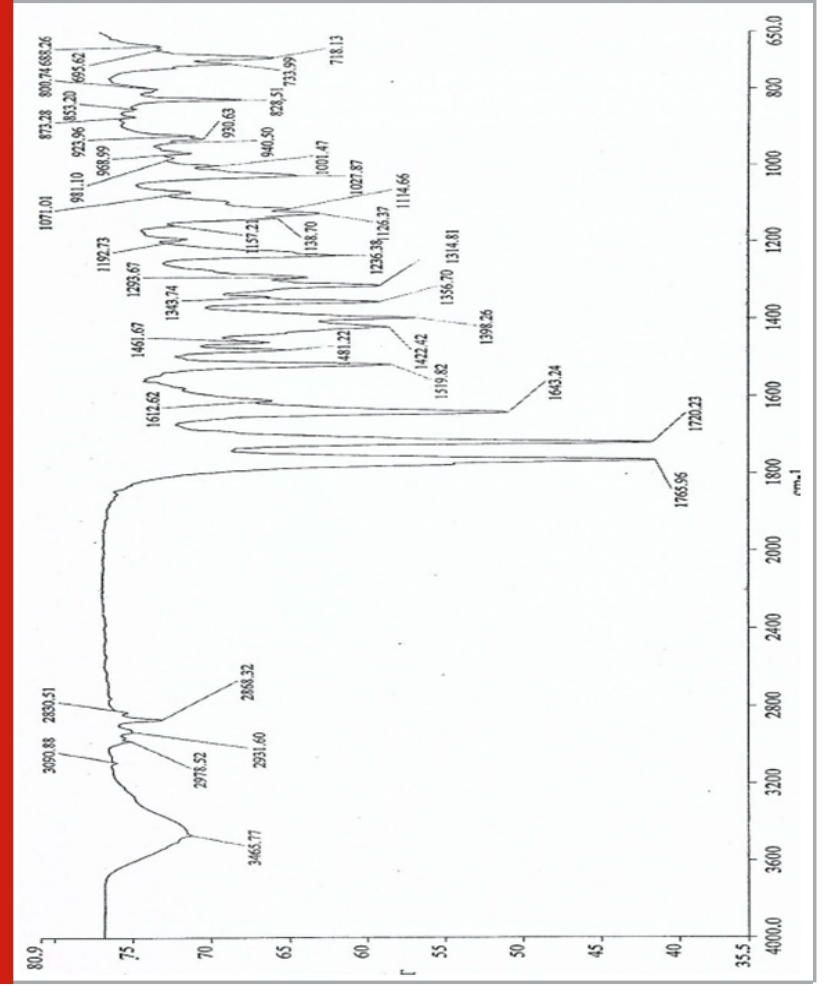

Figure 8: Mass 2-((2-oxo-3-(4-(3-oxomorpholino) phenyl) oxazolidin-5-yl) methyl) isoindoline-1, 3-dione

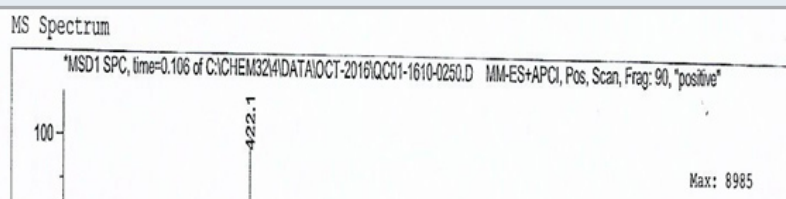

B.No: : \#072

ESTIMATION MASS : 421.46

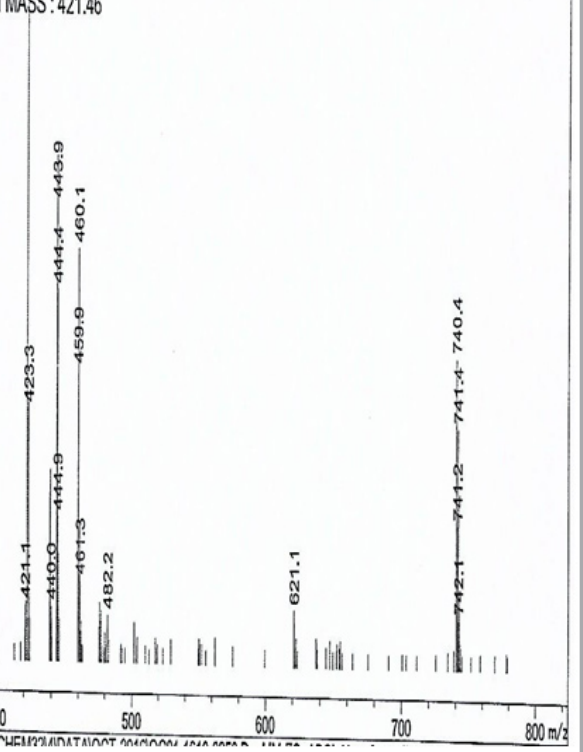

Figure 10: 1H NMR 4-(4-(5-(amino methyl)-2oxooxazolidin-3-yl) phenyl) morpholin-3-one

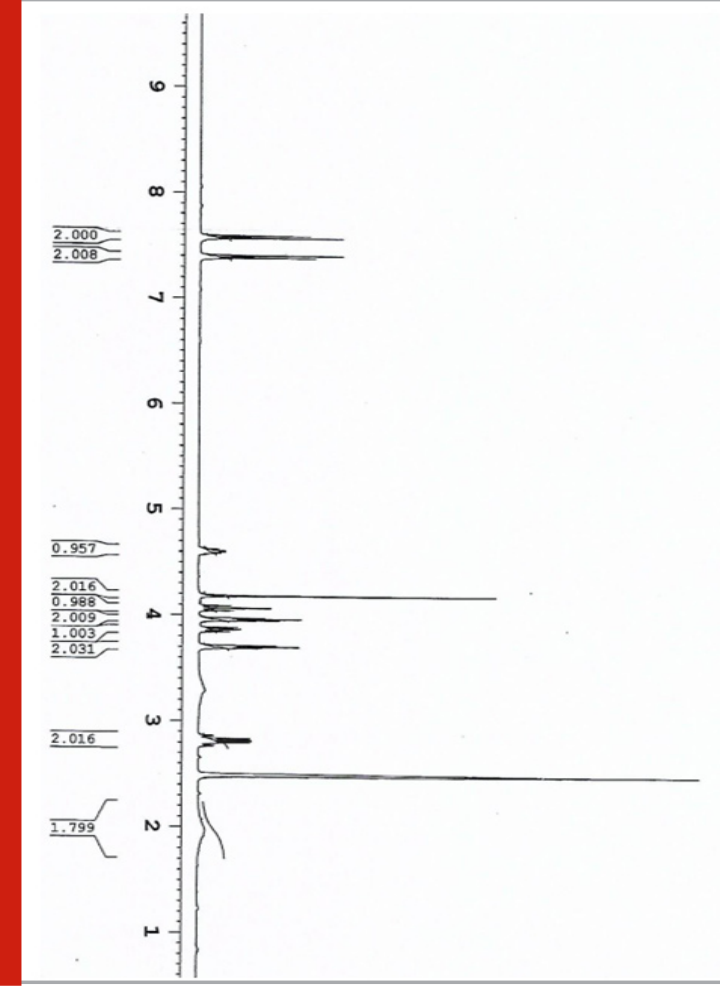


Figure 11: 13C NMR 4-(4-(5-(amino methyl)-2oxooxazolidin-3-yl) phenyl) morpholin-3-one

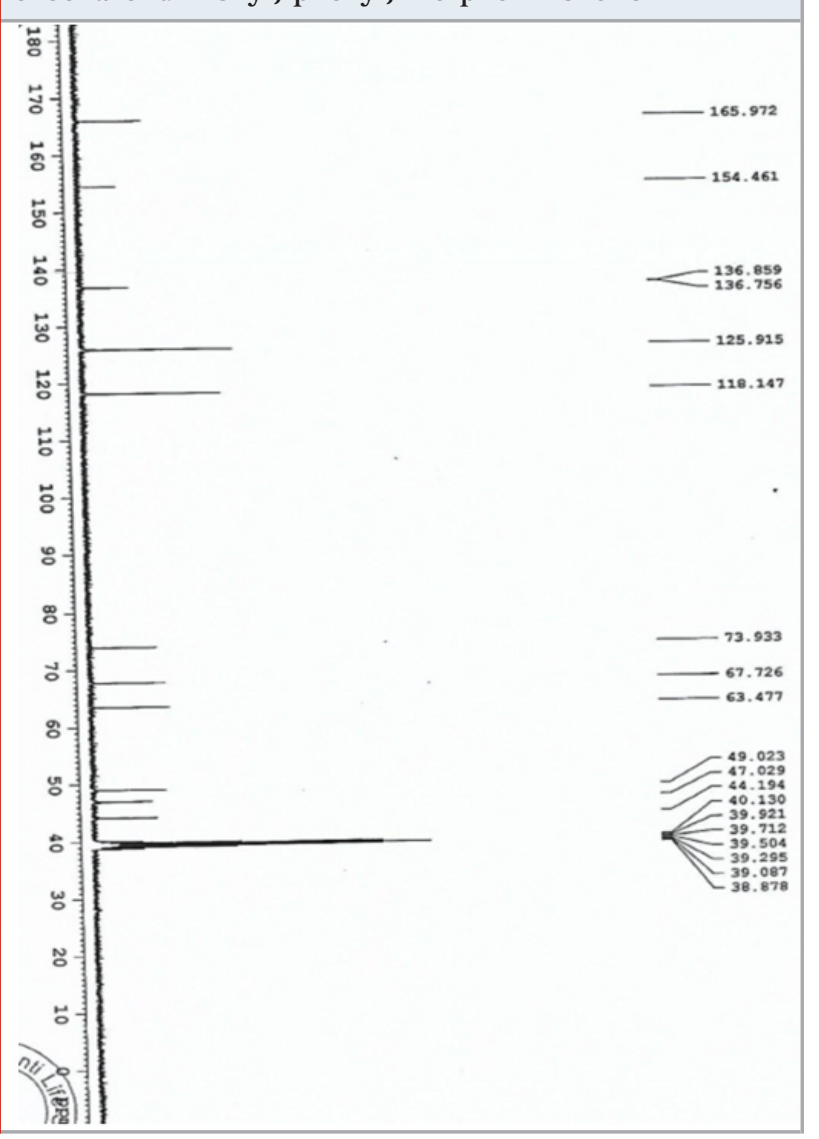

Figure 13: 1H NMR 5-chloro-n-((2-oxo-3-(4-(3oxomorpholino) phenyl) oxazolidin-5-yl) methyl) thiophene-2-carboxamide

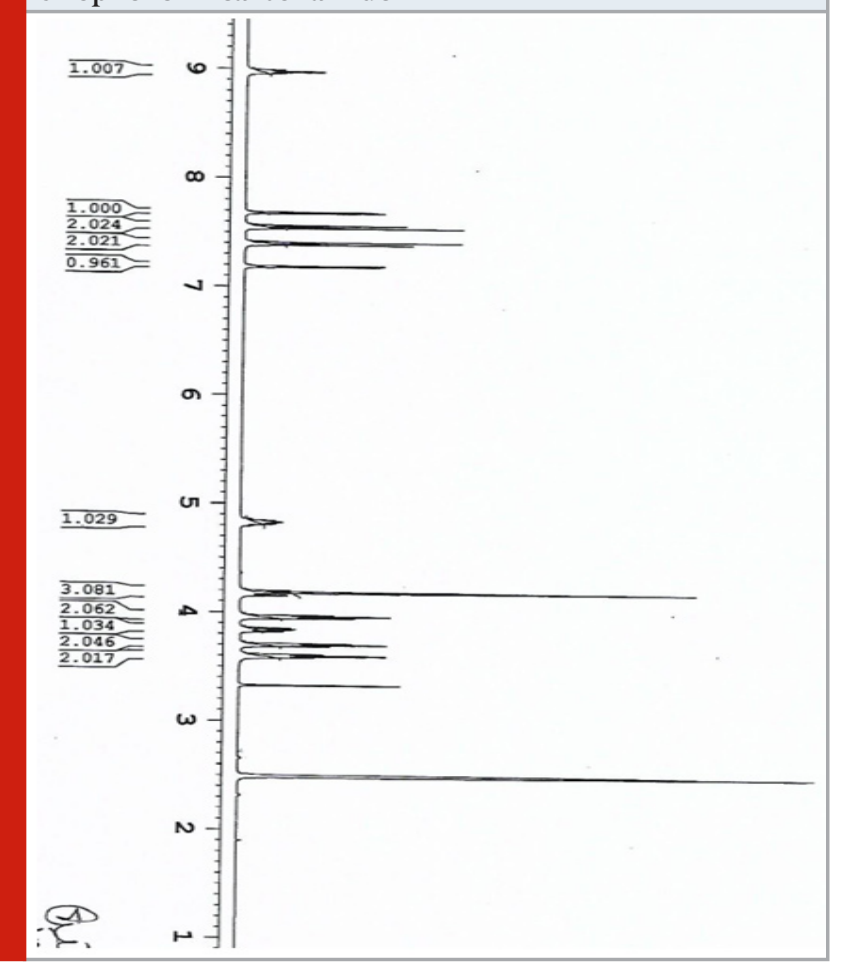

Figure 12: Mass 4-(4-(5-(amino methyl)-2-oxooxazolidin3-yl) phenyl) morpholin-3-one

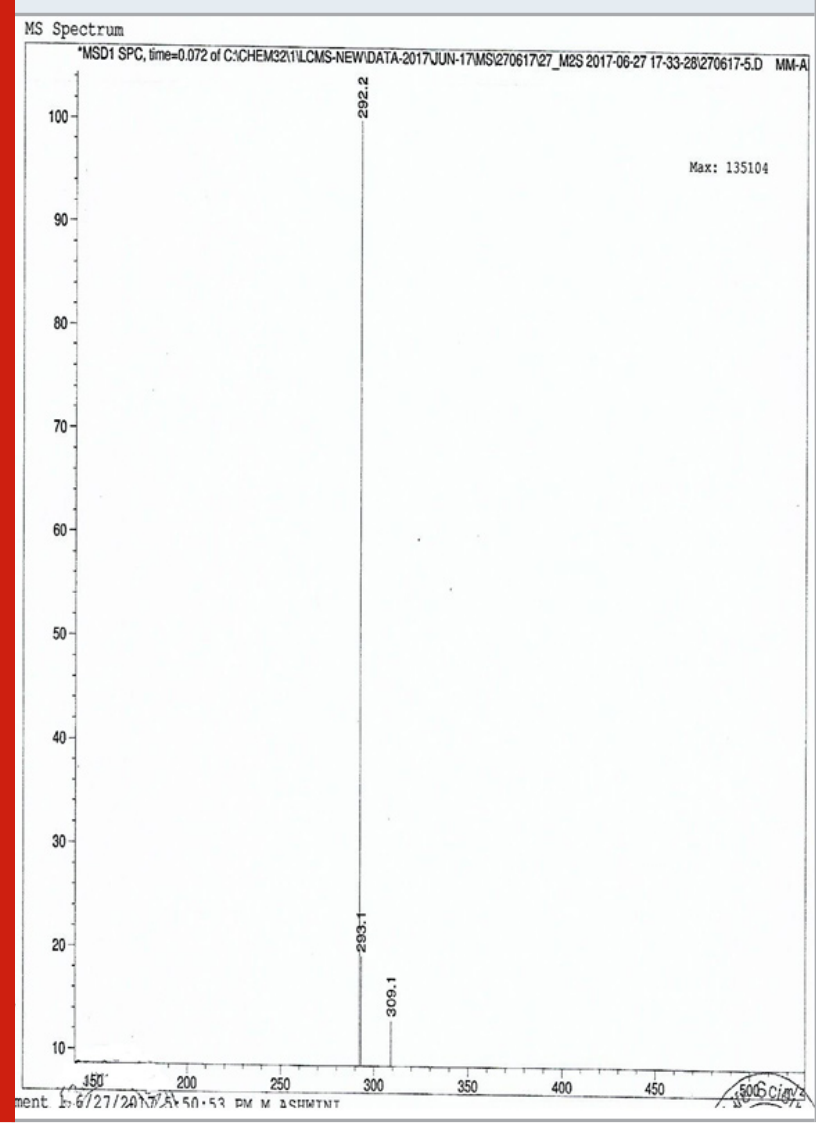

Figure 14: 5-chloro-n-((2-oxo-3-(4-(3-oxomorpholino) phenyl) oxazolidin-5-yl) methyl) thiophene-2carboxamide

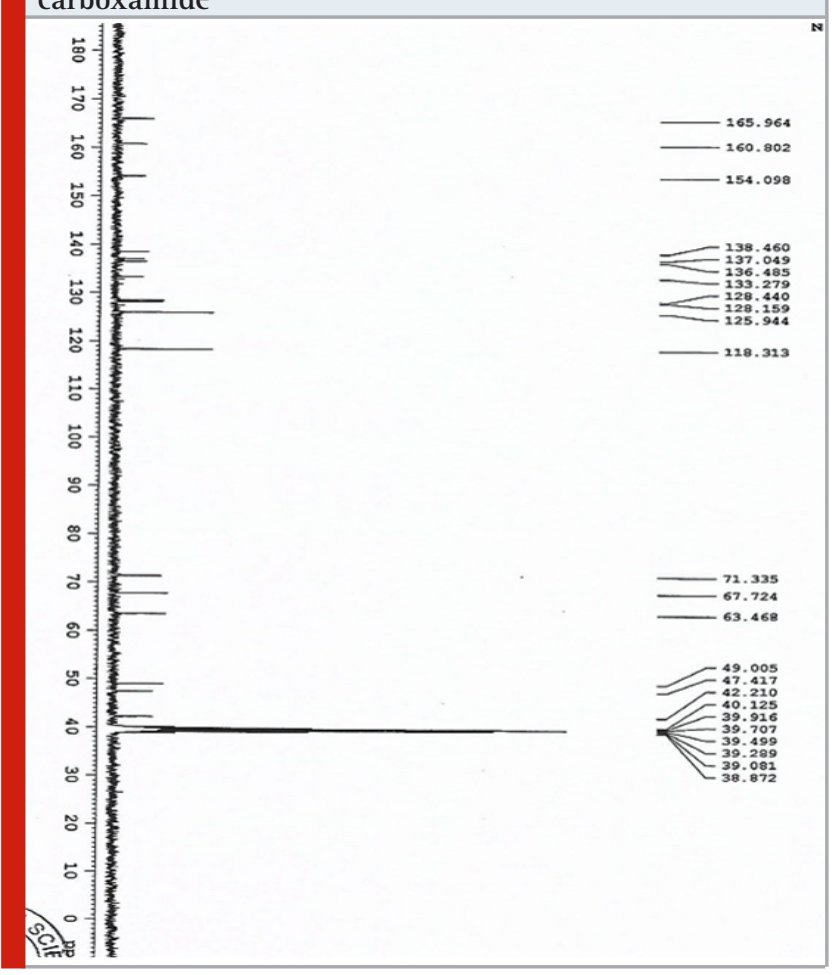


Figure 15: Mass 5-chloro-n-((2-oxo-3-(4-(3oxomorpholino) phenyl) oxazolidin-5-yl) methyl) thiophene-2-carboxamide

06-1 \#65 RT: $0.58 \quad$ AV: 1 NL: 6.06 E2

$06-1 \# 65$ RT: 0.58 AV: 1 NL: $6.06 E 2$
F: ITMS + c ESI Full ms [50.00-2000.00]

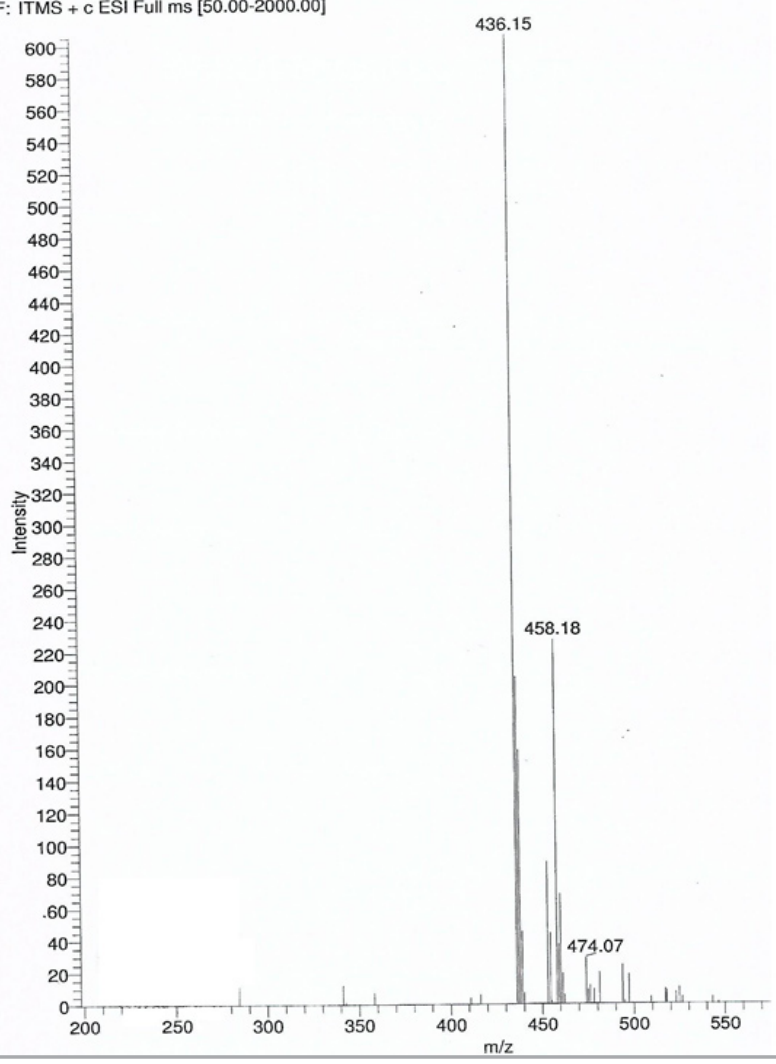

\section{CONCLUSION}

In conclusion, the present paper summarizes the improved synthetic approach utilized for the synthesis of the anticoagulant drug rivaroxaban. The synthetic approach of rivaroxaban was made by introducing a new oxazolidine ring formation with commercially available carbamide in presence of strong base like potassium hydroxide in toluene as solvent that could be used for the industrial production of rivaroxaban in high yield and enantiopurity.

\section{ACKNOWLEDGEMENTS}

The authors are thankful to Department of Chemistry, RVR \& JC Engineering College, Guntur, A.P, India for providing encouraging environment and facilities for research work.

\section{REFERENCES}

Abdulsattar Y, Bhambri R, Nogid A (May 2009). "Rivaroxaban (xarelto) for the prevention of
Figure 16: FT-IR 5-chloro-n-((2-oxo-3-(4-) 3oxomorpholino) phenyl) oxazolidin-5-yl) methyl) thiophene-2-carboxamide

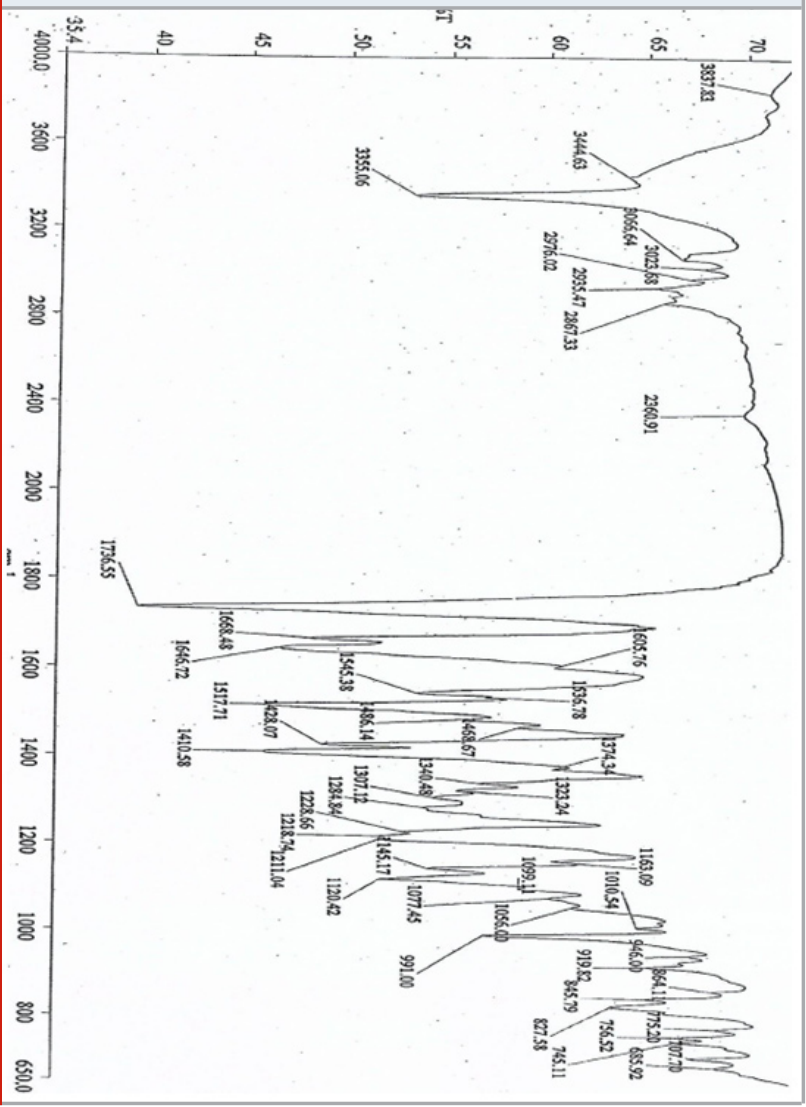

thromboembolic disease: an inside look at the oral direct factor xa inhibitor". P \& T. 34 (5): 238-44.

Alexander, G.; Kuang-Chao, W.; Hsiu-Wen, L.; Ji-Wang, C. Tetrahedron: Asymmetry 1996, 7, 1648.

Hara, T.; Fukuda, D.; Tanaka, K.; Higashikuni, Y.; Hirata, Y.; Nishimoto, S.; Yagi,S.; Yamada, H.; Soeki, T.; Wakatsuki, T. Atherosclerosis 2015, 242, 646.

Mueck, W.; Stampfuss, J.; Kubitza, D.; Becka, M. Clin. Pharmacokinet. 2014, 53,16.

Perzborn, E.; Roehrig, S.; Straub, A.; Kubitza, D.; Misselwitz, F. Nat. Rev. Drug Disc. 2011, 10, 75.

Rivaroxaban Monograph for Professionals". Drugs. com. American Society of Health-System Pharmacists. Retrieved 3 March 2019.

Roehrig, S.; Straub, A.; Pohlmann, J.; Lampe, T.; Pernerstorfer, J.; Schlemmer, K.-H.; Reinemer, P.; Perzborn, E. J. Med. Chem. 2005, 48, 5908.

Turun, S.; Banghua, L.; Yuan, Y.; Zhenhui, L.; Ying, N.; Jin, C. Thromb. Res. 2011, 127, 534.

Yeh, C. H.; Fredenburgh, J. C.; Weitz, J. I. Circ. Res. 2012, 111, 1078. 